\title{
An Examination of Food Waste as a Corporate Social Responsibility of the Retail and Wholesale Sector
}

\author{
Verena Gruber, Christina Holweg, and Christoph Teller
}

\begin{abstract}
Food waste is a major problem in industrialized nations. In order to develop efficient mechanisms for minimization, a better understanding of the complexities involved in food waste is necessary. This chapter takes a marketing system perspective to provide a holistic exploration of the edible food waste phenomenon on a retail and wholesale store level. By means of 32 in-depth interviews with store managers, we gain insights into the relevance of food waste occurrence, avoidance, and redistribution. The data reveals various factors influencing the occurrence of food waste along formal, informal, and philosophical antecedent classes. We find that managing edible food waste is closely connected to the triple bottom line: reducing its occurrence and enabling processes to redistribute edible food waste can create economic, ecological, and social benefits. Against this background, we propose a dormant sustainability potential in the management of food waste and advance recommendations for realizing these benefits. We suggest that food waste is a key priority area in the realm of corporate social responsibility for retail and wholesale organization. The chapter draws on a framework for public policy change and provides a discussion about how different processes can help reduce edible food waste among various market actors.
\end{abstract}

\footnotetext{
V. Gruber $(\bowtie) \bullet$ C. Holweg

WU Vienna, Vienna, Austria

e-mail: verena.gruber@wu.ac.at; christina.holweg@wu.ac.at

C. Teller

University of Surrey, Guildford, UK

e-mail: c.teller@surrey.ac.uk
}

L. Petruzzellis, R.S. Winer (eds.), Rediscovering the Essentiality of Marketing, Developments in Marketing Science: Proceedings of the Academy of Marketing Science, DOI 10.1007/978-3-319-29877-1_82 